\title{
"Eco-Logical" Engineering: A teaching-research model to foster students' paradigm thinking of wastes as commodities
}

\author{
AD O'Sullivan $^{+}$ \\ Hydrological and Ecological Engineering Group, \\ Department of Civil and Natural Resources Engineering, University of Canterbury, New Zealand
}

\begin{abstract}
SUMMARY: Civilisation's quality of living and vitality of their economy are inextricably linked to healthy ecosystems. Engineers harvest the earth's biophysical resources and generate ensuing wastes, so are critical players for ensuring that ecosystems can support current and future sustainable civilisations. Educating future generations charged with mitigating environmental degradation through resource conservation is essential for sustainability to eventuate. This can be fostered through teaching "Eco-Logical" Engineering. Natural Resources Engineering students at the University of Canterbury engaged in prescribed desktop research to recognise capital in waste streams. Projects adopted decentralised engineering solutions in partnership with local ecosystems to ensure survival of the interdependent biotic and fiscal economies. All projects aligned with the core principles of ecological engineering with a particular focus on mass conservation and were contextual, real-world national problems. Students identified that sustainable engineering solutions in New Zealand require integrated technical robustness, promising cost-benefit returns and ecological connectivity. Pedagogical outcomes include helping equip students with the knowledge, technical insight, creativity and context required for challenging and complex problem-solving in the engineering profession.
\end{abstract}

\section{INTRODUCTION}

Engineers are charged with important technical and business decisions on projects that modify the natural environment by consuming biophysical resources and generating ensuing wastes (Head, 2009; Mitchell, 2000). As economies grow, there is a limit to the availability of raw resources and to the assimilation capacity of Earth to process waste products (Head, 2009; Meadows et al, 1972). Hence, there is a pressing need to exercise resource conservation facilitated through material reuse (Clift, 1998). It is argued that in order to optimise resource use efficiency with concomitant waste minimisation, a systems approach is critical in research and in practice (Baumann et al, 2002). According to the $2^{\text {nd }}$ Law of Thermodynamics, all technology inevitably produces material entropy, which are typically waste by-products. High energyintensive technologies lead to large amounts of waste

* Paper D09-074 submitted 29/08/09; accepted for publication after review and revision 20/04/10.

+ Corresponding author Dr Aisling O'Sullivan can be contacted at aisling.osullivan@canterbury.ac.nz. that become harder for ecosystems to assimilate, since high entropy wastes are incompatible with the low entropy inherent in nature's biosystems. A logical solution to this incompatibility is to develop engineering solutions based on whole systems integration that capitalise on embodied energy in waste products. These wastes thus become realised as feed streams for other technologies and so serve as a new commodity or reusable resource.

Society has become increasingly concerned about waste generation (eg. Clift, 1998) especially as New Zealand markets its lucrative tourist economy on the "clean-green" image. Recent national policies, including the 2002 Waste Strategy, provided impetus for achieving a vision and target of zero waste initiatives. The New Zealand Ministry for the Environment reported that $93 \%$ of raw materials are discarded during processing and do not end up as saleable products (Environment New Zealand, 2007). Consequently, the government is actively promoting a paradigm shift in waste management as a means of disassociating the volume of waste generated and economic growth, as outlined in the 2007 cabinet policy paper "POL (07) 132 - Towards a Sustainable 
New Zealand". This aims to achieve economic wealth without compromising our environmental capital and is a good step towards implementing sustainable development through triple-bottomline (ecologic, economic and social) principles. It is therefore relevant to reassess how we manage our wastes and seek creative and innovative yet cost-effective opportunities to reuse these wastes. This rethinking in the waste management sector has been previously outlined (Clift, 1998) and the paradigm shift is essential so that many wastes can actually be realised as commodities or "misplaced" resources. This was the motivation for prescribing the "wastes to commodities" undergraduate research assignment that presents as a teaching model to foster integrated problem-solving and creativity required for sustainable engineering.

Engineers are responsible for creative and innovative solutions to solve challenging technical problems (Head, 2009). As such, it is important to facilitate creative opportunities in an engineering learning context to enable graduates to practice creative, challenging and sustainable problem solving facilitating professional intrapreneurialship (Menzel, 2007). In a prerequisite course (Ecological Engineering 1), engineering students learnt the theoretical principles of "Eco-Logical" Engineering, including resource conservation. By cementing these fundamentals in a desktop research assignment presented here, students were empowered to think creatively and in an integrated holistic manner, while seeking practical solutions for reducing our nation's waste footprint. This paper presents a model (with detailed results) of how engineering students were guided in seeking sustainable solutions for realworld and contextual waste engineering challenges through ecological engineering research.

Ecological engineering is a discipline established in Europe and North America about 30 years ago, but with roots in ancient China (Odum \& Odum, 2003). It integrates ecological sustainability with technical problem-solving and design by adopting the approach of engineering in partnership with nature (Mitsch, 2001). Key principles of ecological engineering as distinct from other engineering disciplines include: (i) resource conservation through "recycling"; (ii) employing a systems approach; and (iii) facilitating self-design. Conservation of resources by cycling was the theoretical principle of focus in the prescribed waste to commodities assignment described here.

\section{METHODOLOGY}

\subsection{Curriculum structure}

The Natural Resources (formerly Agricultural) Engineering program at the University of Canterbury has been accredited by the Institution of Professional Engineers New Zealand since 1967 and is internationally recognised through the Washington Accord. It is somewhat unique (Painter, 2003), although closely related to international programs in biological, biosystems, bioresources, ecological and agricultural engineering, which are well reported (Bergen et al, 2001; Johnson, 2006; Krutz \& Schueller, 2000). Students in their final (honours) year of the program are currently required to take 10 courses (eight are core) of equivalent weighting in the academic year. Each course has an imposed maximum lecturer-student contact time of 30 lectures plus 12 hours of laboratories and/or tutorials (total contact 48 hours per course). Students are expected to spend up to 120 hours working on each course.

\subsection{Research assignment}

One of the core courses is titled Ecological Engineering 2 , in which students were assigned the task of conducting an individual (equivalent to 40 hours) desktop research study that demonstrated value from reusing waste streams. This course was established in 2006 following major university engineering curricula changes. No similar course was previously taught, although aspects of traditional waste engineering were included in a previous course, albeit instructed in a conventional waste engineering approach (ie. without ecological integration). Therefore, the timing was opportune to enhance engineering students' appreciation for the ecological connectedness of their professional activities through ecological engineering instruction. Since it was their first exposure to research, students were provided with a prescribed project brief and relevant example from overseas. Examples included mining waste reuse in the North American Appalachia, urine separation toilets in Scandinavia, construction bricks made from coal dust in China, biogas from tannery fats in Europe, and coal seam gas wastewater used for irrigation in the semi-arid Midwestern USA. Ecological engineering is a trans-disciplinary field and the diversity of projects documented in this study reflects that breadth. However, all projects had the same scope as defined in the project brief and aligned to the core principles of working in partnership with nature while maintaining the material loops closed, thus exercising material and energy conservation. The objectives of this assignment are listed below.

\subsubsection{Objectives}

1. To design integrated treatment technologies for complex wastes - eg. coupling ecosystems and engineering.

2. To relate ecosystem processes with sustainable waste management - abiotic and biotic dynamics, where relevant.

3. To develop creative entrepreneurial skills by incorporating ecological economics and some 
cost-benefit analysis into the proposed treatment technology.

4. To expand technical report writing and communication skills.

\subsubsection{Topics students received prior instruction in related to assignment}

It was a requirement that projects aligned their technical solutions to the principles of ecological engineering as learnt in two courses. The first (prerequisite) course Ecological Engineering 1 introduced the fundamental principles and some case studies of this engineering trans-discipline, while the second course, Ecological Engineering 2, cemented those fundamentals by building on its prerequisite course with more of a design focus through detailed applications. No practical component in either of these relevant courses was directly applicable to the "wastes to commodities" assignment.

In order to assess the feasibility of implementing the technical solution in New Zealand, students were instructed in relevant legislation, policies and standards that would need to be addressed, along with introductory ecological economics to assist them with deriving a rudimentary cost-benefit analysis. An outline of the specific topics in which students received relevant instruction for the assignment is presented in table 1. Each lecture was 50 minutes long, while a 1-hour tutorial guiding students on "how to approach the semester project" was also delivered. External stakeholders including local (and regional) government, as well as practising engineers were contacted by email and/or phone during the student led investigations. These were conducted on a fairly ad-hoc basis and typically facilitated by the instructor who had established collaborative relationships with these external parties.

\subsubsection{Assessment}

Students were required to write an engineering report ( $<7000$ words) on the technical design and project feasibility for treating a specific (chosen) waste stream in the New Zealand context. Additionally, they were required to present a synopsis of their specific research ( $<15$ minutes) in a seminar setting. All students were supported in locating appropriate and relevant literature, as well as contacting external stakeholders. The aim of liaising with relevant external parties was multiple. It provided some "inhouse" technical data that was not reported in widely available material, helped students appreciate likely logistical obstacles to project implementation in the real-world, and taught them the value of consulting time and the associated requirement to plan ahead as responses were not immediate. By process, it also helped students connect research with real-world practical problem-solving so their efforts became contextual and relevant. Students had eight weeks to produce the report, which constituted $20 \%$ of the course mark (equivalent to $2.0 \%$ of the academic year assessment). An additional 5\% was allocated to the individual oral presentation. Each technical report was marked by the primary instructor (the author of this paper) and independently by a graduate research assistant adopting the criteria listed in table 2. Additionally, students were provided with one of their colleague's reports to confidentially peer assess following the same criteria. Students were advised that it is unlikely their peer would score greater than $17 / 20$ unless it was an exceptional report or below $10 / 20$ unless it was exceptionally weak. Since a clause was also included to the effect that if students were late in providing an assessment of their peer's report they would incur a significant deduction for their own project, no peer reviews were submitted late.

\section{RESULTS AND DISCUSSION}

\subsection{Project summaries}

Figure 1 depicts a typical assessment model that integrates ecological (natural), social (human), technical and financial (support) domains considered in each project. The natural components included

Table 1: Specific topics in which students received relevant prior instruction.

\begin{tabular}{|l|c|}
\hline Topic & \multicolumn{1}{|c|}{ Number of lectures } \\
\hline Principles and practice of ecological engineering & 4 \\
\hline Ecosystem self-designs and energy signatures & 3 \\
\hline Ecological engineering applications (global) & 6 \\
\hline Ecological engineering applications (New Zealand) & 8 \\
\hline Sustainable engineering: contextual applications & 4 \\
\hline Managing wastes the Eco-Logical Engineering way & 3 \\
\hline Ecological accounting & 4 \\
\hline Environmental policies, regulations, standards and legislation & 4 \\
\hline & 36 (total) \\
\hline
\end{tabular}


Table 2: $\quad$ Criteria for assessing technical reports and associated weighting.

\begin{tabular}{|l|c|}
\hline Criteria & Percentage of course \\
\hline Articulate technical content (including design specifications) & 4 \\
\hline Linking objectives and conclusions & 3 \\
\hline Appropriate literature review & 4 \\
\hline Report structure, grammar, presentation of results, etc. & 4 \\
\hline Wow factor; creative ingenuity and recommendations & 2 \\
\hline Discretionary marks for excellence & 1 \\
\hline Project feasibility (NZ context) ${ }^{a}$ & 2 \\
\hline & 20 (total) \\
\hline${ }^{a}$ With a premise of technical, logistical and triple-bottom-line implementation/consideration. \\
\hline
\end{tabular}

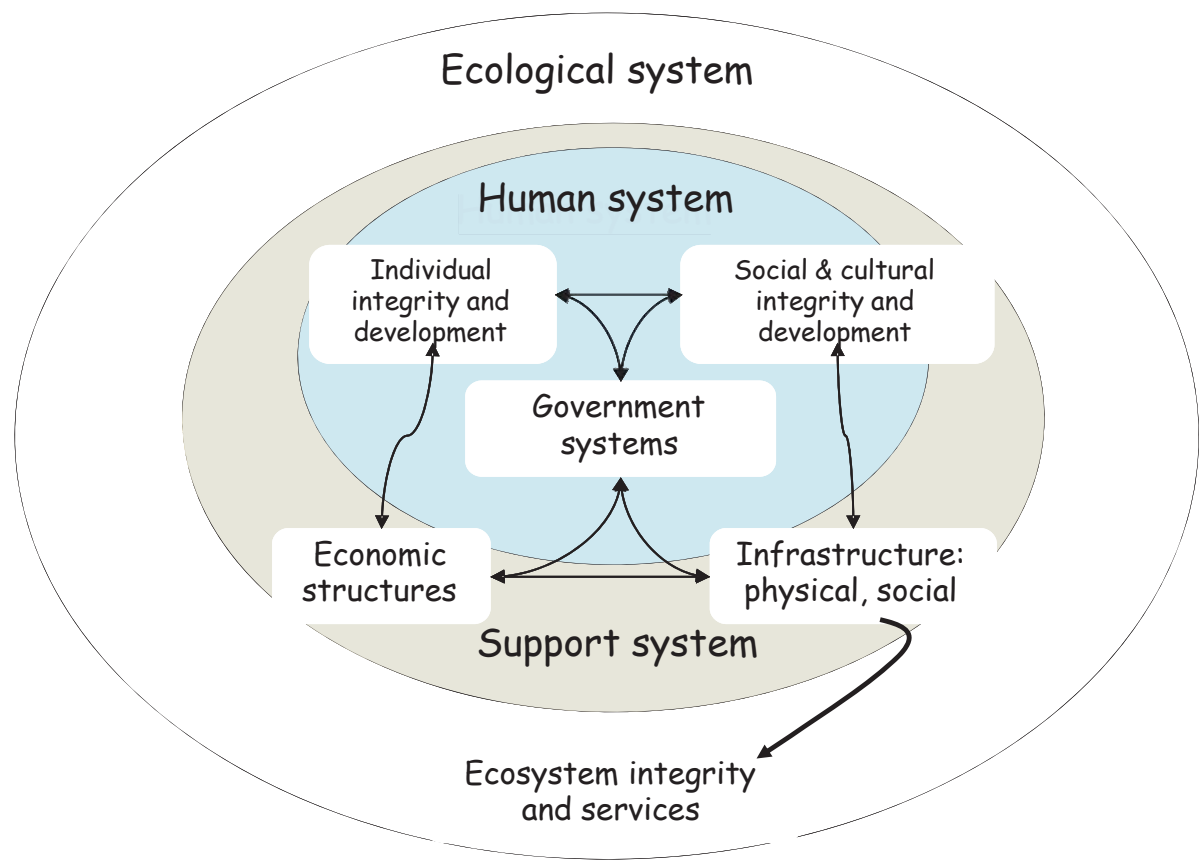

Figure 1: Integrated ecological (natural), social (human) along with technical and financial (support) criteria considered in each project proposed (after A. Dakers).

potential habitat impact(s) and material flows, while the human system criteria included community impact(s) such as cultural integration, job creation and educational value that could result. Infrastructural and fiscal support comprised the main support system considerations. These guideline considerations were provided to students to assess and discuss within their projects, but were not assessed in a quantitative manner. Overall, students focused their projects on the premise of resource reuse with minimal net ecological impact.

All projects were required to address the technical, social and ecological integration and feasibility in the New Zealand context while providing a basic cost analysis. Furthermore, projects aimed at adhering to the proximity principle whereby waste streams were reused close to their source, thus reducing transport requirements or transfer of wastes to ecosystems beyond their zone of generation.
A summary of waste streams and their recognised use (recovered resource) is given in table 3. A synopsis of the conclusions from each desktop research project is also provided, which was generated from the research project briefs provided to students and some of the research results. This information could serve a valuable, contextual resource for other sustainable waste engineering courses or as a similar teachingresearch model so is therefore provided in detail.

\subsubsection{End-of-life vulcanised vehicle tyres}

\subsubsection{Erosion control mattresses}

The USA and European Union recover more than $75 \%$ of used tyres, but $75 \%$ of the 4 million used tyres produced annually in New Zealand are disposed to landfill resulting in hazardous stockpiles (TyreTrack, 2008). The remainder are converted into granulated 
Table 3: Ecological engineering desktop research projects that realised capital in waste streams.

\begin{tabular}{|l|l|l|}
\hline Waste category & Waste stream & Recovered resource \\
\hline $\begin{array}{l}\text { End-of-life vulcanised } \\
\text { vehicle tyres }\end{array}$ & End-of-life tyres & Erosion control "mattresses" \\
\cline { 2 - 3 } & End-of-life tyres & Energy via reverse polymerisation \\
\hline \multirow{4}{*}{ Used recyclable glass } & Glass cullet & $\begin{array}{l}\text { Roading aggregate and permeable } \\
\text { paving blocks }\end{array}$ \\
\cline { 2 - 3 } $\begin{array}{l}\text { Coal and metaliferous } \\
\text { mining wastes }\end{array}$ & Glass bottles (uncrushed) & Glass Goblets and tumblers \\
\cline { 2 - 3 } & Acid mine drainage iron-oxide(s) & $\begin{array}{l}\text { Dye pigments for paints, textiles, } \\
\text { plastics, paper and cements }\end{array}$ \\
\cline { 2 - 3 } & Abandoned underground mine water & $\begin{array}{l}\text { Geothermal energy for heat pump } \\
\text { systems }\end{array}$ \\
\cline { 2 - 3 } & Metaliferous mine tailings & Cement blocks \\
\cline { 2 - 3 } & Fly ash and sewage sludge & Soil amendment \\
\hline \multirow{3}{*}{ Organic wastes } & Human urine (via separation toilets) & Fertiliser \\
\cline { 2 - 3 } & $\begin{array}{l}\text { Fish and potato processing by- } \\
\text { products }\end{array}$ & Fish feed pellets \\
\hline \multirow{3}{*}{ Plastics } & Biodegradable plastics & Fertiliser \\
\cline { 2 - 3 } & Plastic bottle tops & $\begin{array}{l}\text { Biofilm media for domestic wastewater } \\
\text { treatment }\end{array}$ \\
\hline
\end{tabular}

rubber from shredding or used on farms to secure silage bales. Dumped tyres represent an enormous amount of unused embodied energy and take more than 200 years to breakdown in the environment. Tyre mattresses can provide an effective erosion control measure that capitalises on used tyres to solve an erosion problem. Used tyres are connected together using strong tensile cables and placed at strategic locations in the catchment to dissipate energy that causes soil erosion. The design does not require modification of the used tyre or substantial transport costs; both of which would incur energy costs. A laboratory test revealed satisfactory erosion control under flow velocities ranging from 0.6 to $1.52 \mathrm{~m} / \mathrm{s}$ (Amari et al, 1999). Although well developed overseas, this technology has the capacity to be exploited in New Zealand and hence better align with the New Zealand 2002 Waste Strategy.

\subsubsection{Energy via reverse polymerisation}

Another opportunity to capitalise on stockpiled used tyres in New Zealand is through reverse polymerisation, which uses microwaves to break down the tyre into its original constituents (principally styrene-butadiene vulcanised rubber, carbon black, steel wire and zinc oxide), as well as recovering energy in the process. These components are typically of sufficient grade to be reused in rubber production, which supersedes the quality of tyre components from pyrolysis and thus are attractive alternatives to their virgin equivalents. The estimated embodied energy provided from discarded used tyres in New Zealand amounts to $2.2 \times 10^{7} \mathrm{GJ}$; enough to power 566,000 homes, although the efficacy of the reverse polymerisation process in recovering this as fuel energy is estimated at only $37 \%$ (Karlik-Neale, 2006). Two cement companies in New Zealand were identified as potential candidates for employing used tyres directly as an energy source, which would be feasible given the complete combustion afforded in cement kilns and the greater specific energy content compared to coal (1 kg tyre versus $1.3 \mathrm{~kg}$ coal). However, reverse polymerisation reduces carbon dioxide emissions by reusing the carbon black constituent (saving on an energy intensive process) and also produces hydrocarbons lower in sulphurous emissions compared to tyre combustion alone. While the capital costs estimated with establishing a reverse polymerisation plant in New Zealand are estimated between NZ\$12.8 to $\$ 30.8$ million, cost savings afforded by carbon credit gains could be enormous.

\subsubsection{Used recyclable glass}

\subsubsection{Roading aggregate and permeable paving blocks from glass cullet}

Approximately $49 \%$ of the $185,000 \mathrm{t} / \mathrm{a}$ of reusable glass collected in New Zealand is shipped to the country's only recycling company, which is located in the North Island, while the remainder is stockpiled. This situation does not assist South Island communities with reusing a waste resource given the inherent economic challenges (NZ\$200/tonne freight versus NZ\$65/tonne for resource) and concomitant ecological impacts associated with transport. Up to $5 \%$ glass cullet substitution in the base course of standard flexible 
pavements in New Zealand conforms to the national road standards (Transit New Zealand, 2006), while this amount could be increased to $20 \%$ given a review of the current standards. Ideally $10 \%(10 \mathrm{~mm})$ cullet in the base course providing drainage, frost protection and additional load bearing capacity in addition to $10 \%$ in the upper wearing layer $(4.75 \mathrm{~mm})$ providing friction, noise control and drainage could assist reuse of the stockpiling waste glass. Additionally, glass cullet could be incorporated into permeable paving systems as aggregates. No modifications to machinery are envisaged in order to substitute glass for traditional aggregates making this a feasible opportunity to capitalise on waste glass. As this has not yet been tested in New Zealand permeable pavements, material properties would need to conform to appropriate standard codes, including breaking loads, thickness, abrasion resistance, drainage and coefficient of friction (NZS 3116:2002) and appearance (NZS3114:1987). Given the chemical incompatibility of cement and glass through an alkali-silica reaction, ameliorants to mitigate this should be incorporated including other waste products such as fly ash, furnace slag and finely crushed glass itself (Shayan \& Xu, 2004). This reaction is not as pronounced with green glass due to its chrome content. The economic cost savings associated with crushing glass is NZ\$32/tonne over landfill stockpiling, which could also provide substantial ecological and social benefits over the status quo.

\subsubsection{Glass goblets and tumblers from uncrushed glass}

Uncrushed glass could also be reused in New Zealand whereby energy is conserved through lack of crushing and/or in the recycling process. This could be modelled on a technology demonstrated overseas where business environments are compatible to that in New Zealand. To be most effective, uncrushed bottles should be collected from businesses incurring large waste glass volumes. Individual glass bottles can be made into one tumbler (from a $330 \mathrm{~mL}$ bottle) or one goblet and one tumbler (from a $750 \mathrm{~mL}$ bottle) through strategic cutting, tempering and finishing (including etching to advertise a logo). The main opportunity to capitalise on reusing uncrushed waste glass in New Zealand is through marketing such a creation as a niche boutique product, perhaps endorsed by an eco-warrior celebrity. This endeavour would undoubtedly stimulate and encourage entrepreneurial attitudes towards problems of resource reuse.

\subsubsection{Coal and metaliferous mining wastes}

\subsubsection{Dye pigments from acid mine drainage iron-oxide(s)}

Historical and active coal mining in New Zealand causes acid mine drainage (AMD) impacting the ecological integrity of many waterways (McCauley et al, 2009). Treating this wastewater usually involves converting the metals present, such as iron and aluminium, from dissolved to solid forms resulting in iron-oxide sludge. Presently this is accomplished by active lime dosing or passively in treatment wetlands. Previously, the value of this sludge was unrealised and disposed to landfill, but markets overseas have proven it to be a valuable commodity as a suitable pigment for the paint, textile and cement industry. The process involves recovering the iron-oxide sludge from treatment ponds followed by dewatering and pressing into a "filter cake" product. Estimating the production potential of iron-oxides in New Zealand assumes a concentration of $140 \mathrm{mg} \mathrm{Fe} / \mathrm{L}$ in AMD and a design flow rate of $35 \mathrm{~L} / \mathrm{s}$ with $99 \%$ removal efficacy, which is reasonable (McCauley et al, 2009). This would provide approximately $77,000 \mathrm{~kg}$ of (dried) processed iron sludge equating to between NZ\$304,000 to NZ\$482,000 economic returns per annum based on current retail prices for iron-oxide pigmented paints. Given that AMD is a growing problem in New Zealand and that leading coal companies reported their environmental liabilities at NZ\$139 million in 2007, recovering iron-oxide pigments from AMD treatment is a promising opportunity to offset some of these economic and ecological costs inherent in coal mining. Furthermore, improved product stewardship from this opportunity makes this a venture for companies who are undergoing increasing environmental scrutiny.

\subsubsection{Synthetic steel slag as an alkaline ameliorant and surface media for $\underline{\text { AMD treatment }}$}

Steel slag, a non-metallic stable by-product of steel production, is a highly alkaline (eg. 35\% Ca, $8 \% \mathrm{Mg}$ ) solid material with a high surface area to volume ratio. This makes it an ideal media for neutralising acidity from AMD while concurrently enhancing abiotic iron-oxide formation in its porous surface (Hamilton et al, 2007). An advantage of using steel slag over limestone in AMD treatment is that (i) it is a waste product and (ii) it does not armour with iron-oxides as rapidly. Approximately $79 \%$ of the steel slag produced annually in New Zealand is reused, recycled or sold; mainly in roading aggregate or drainage following crushing. A proposal to reuse more of this slag without the requirement for crushing is to treat AMD in drainage channels for dissolved acidity and iron removal. Conceptually this could be facilitated by partnering two lucrative New Zealand industries (coal mining and steel production) for economic gain and ecological enhancement. Rudimentary cost analysis indicates that if these two industries can collaborate locally (such as in the Waikato Region of the North Island), 
significant cost savings from disposal to landfill and reduction in limestone/lime dosing costs can be met (approximately NZ\$6 million per annum).

\subsubsection{Geothermal energy for heat pump systems from abandoned underground mines}

Geothermal energy resources in New Zealand are underdeveloped. This may be due to lack of infrastructure, dominance of hydroelectric resources or inefficacy of high temperature hydrothermal resources, which can damage the geothermal habitat upon extraction. It could also be due to the special guardianship (kaitiakitanga) indigenous Maori communities have with this natural resource, who are cautious about over harnessing its supply, which could compromise its integrity for future generations (Dickie, 2005). However, low grade geothermal heat present in hot and warm springs, and warm water in flooded underground coal and mineral mines could be effective heat sources (Watzlaf \& Ackman, 2006) incurring minimal effects on the environment. New Zealand has 22 abandoned underground coal mines with estimated water temperatures ranging from 18 to $24{ }^{\circ} \mathrm{C}$ and at least nine abandoned gold mines with water temperatures estimated between 19 to $35^{\circ} \mathrm{C}$ (East Harbour Management, 2007). These designated waste areas could be exploited for their heat energy as a means towards responding to increasing energy demands and costs. In order to capitalise on this waste resource accurate mapping of mine workings, to estimate their void volumes and degree of flooding, is required.

\subsubsection{Cement blocks from metaliferous mine tailings}

New Zealand's largest gold mine processes more than 5 million $\mathrm{t} / \mathrm{a}$ of ore, producing $1.4 \mathrm{~g} \mathrm{Au}$ per tonne (OceanaGold Corporation, 2008), resulting in huge volumes (99\%) of sludge waste tailings. This material is currently stockpiled and stored in settling ponds on-site, but is subject to airborne transport during strong dry northwest winds. It is reasonable to suggest that tailings are a suitable material for use in concrete blocks due to their low particle size $(<1 \mathrm{~mm}$ diameter), low permeability and high compactness leading to good pavement wear-resistance (Jeuffroy \& Sauterey, 1996). Overseas research has indicated that in combination with fly ash (and silica fume), $5 \%$ gold tailings used in cement increased the compressive strength and porosity of mortar blocks (Celik et al, 2006). The manufacture of ready mix cement has tripled over the last 25 years in New Zealand with a production volume of more than 3.5 million $\mathrm{m}^{3}$ annually, showing there is an established and increasing market for mortar products. In the current New Zealand resource extraction climate, there is unrealised potential to capitalise on fine tailings wastes by incorporating them into valuable cement structures, which could also enhance immobilisation of hazardous materials and improve ecological integrity of the adjacent environments. Inhibition seems to result from uncertainty regarding resource distribution costs coupled with the cheap availability of other aggregate constituents. By exploring the opportunity to process tailings onsite into mortar products, economic and ecological benefits could be substantial.

\subsubsection{Fly ash and sewage sludge as soil amendments}

New Zealand's soils are predominantly acidic, which is exacerbated by over application of nitrogenous fertilisers to support European-derived pasture and crops. Over intensification of agricultural land has resulted in loss of organic matter, nutrients and structural stability of many New Zealand soils, yet the lucrative agricultural industry relies heavily on their ability to support crop and animal production. Traditional fertilisers used to maintain soil nutrient levels nationally amount to approximately NZ\$600 per hectare of dairy pasture, which is not sustainable economically or ecologically. An alternative approach could be to reuse fly ash and sewage sludge (in combination with lime) as an effective soil enhancer providing alkaline, organic, nutrient and bulking properties necessary for efficient crop growth. This combination of waste products overseas is termed SLASH (Sewage sludge, Lime and fly ASH in a ratio of 3:1:6) and demonstrated considerable soil ameliorant properties resulting in significantly enhanced crop productivity (Truter, 2007). Approximately $150,000 \mathrm{t} / \mathrm{a}$ of fly ash are produced in New Zealand, most of which are disposed to landfill. Fly ash is a fine grained by-product of the coal power industry and contains mainly inorganic material and some partially combusted carbon. Sewage sludge is a byproduct of municipal wastewater treatment plants and is plentiful in essential crop nutrients, including nitrogen, phosphorous and potassium, as well as organic matter. Nationally, it is sometimes termed biosolids and more than 234,112 t/a are produced, of which approximately $65 \%$ is applied to forest land (Environment New Zealand, 2007). The Huntly powerstation in the pastoral agricultural region of Waikato in the North Island is a pragmatic location for processing SLASH in New Zealand due to its proximity to the waste resources and supply market, where local soils are nutrient deficient. Limitations associated with developing SLASH equivalent products in New Zealand may include resistance to applying (human derived) waste products to agricultural land, as well uncertainty regarding metal mobilisation and food crop uptake from the biosolids. It is proposed that with robust field trials in the New Zealand context, fly ash (and sewage sludge) waste could demonstrate considerable economic, social and ecological returns. 


\subsubsection{Organic wastes}

\subsubsection{Fertiliser from human urine (via source separation toilets)}

Although human urine constitutes only $1 \%$ of a household's wastewater, it contains $70 \%$ of nitrogen and $50 \%$ of phosphorous in the total wastewater stream, and unlike faeces, does not generally contain enteric pathogens that can be transmitted through the environment (Larsen et al, 2009). This amounts to an enormous fertiliser resource that could be capitalised upon to (i) reduce synthetic fertiliser material and energy requirements and their associated freight footprint; (ii) reduce treatment loads on municipal sewerage plants; and (iii) demonstrate environmental stewardship with concomitant economic benefits. The technology has been implemented in parts of Scandinavia where this waste has been recognised as liquid gold for the farming sector (Lawton, 2006,). A brief analysis of exploiting human urine in the Canterbury region of New Zealand projected that 69 households, each with $1460 \mathrm{~kg} / \mathrm{a}$ urine produced, are required to fertiliser 1 ha of wheat (with a yield of $8 \mathrm{t} /$ ha annually) indicating that urine alone is not sufficient to maintain high crop productivity. Using human-derived wastes is not yet socially accepted or understood in New Zealand. Source-separation toilet capital costs are greater than regular toilets, while some maintenance costs are also incurred including NZ\$400 annually for collection and disposal, which is double the typical sewerage rates for households connected to reticulated treatment networks. Therefore, it may be more economical for large businesses that can avail of waste tax levies to trial urine separation toilets before they are adopted in residential communities.

\subsubsection{Fish feed pellets from fish and potato processing by-products}

The New Zealand aquaculture industry is growing on average $11.7 \%$ per annum, farming King Salmon, Greenshell Mussels and Pacific Oysters primarily destined for export. Salmon are currently fed on pellets imported from Chile and Australia, which are produced from fish meal and oil manufactured from 750,000 tonnes of wild fish. More than 30,000 tonnes of imported feed are required to sustain the 10,000 t/a of farmed salmon, which is increasing by approximately $3000 \mathrm{t} / \mathrm{a}$ and is unsustainable. In accordance with the New Zealand Aquaculture Sector's vision of "promoting environmental sustainability and integrity of aquaculture", new fish feed streams are required to sustain the industry economically and ecologically. Waste resources employed from the fish (Knuckley, 2004) or potato (Charmley et al, 2006) processing industries overseas demonstrated no noticeable effect on the growth rate or quality of fish produced. Using such waste products reduces the life cycle energy requirements and cost of feed pellets (Pelletier \& Tyedmers, 2007) and is applicable in New Zealand. Projections for New Zealand indicate this could help reduce landfill (trade waste) costs by NZ\$4.8 million per year ( $\$ 160$ per tonne disposal costs $\times 30,000$ tonnes disposed) to the processing industries, as well as intangible ecological returns from reduced imported freight footprints and feed supply security. In order to prevent current processing plants from having to expand their existing infrastructure, raw waste streams could be transported to a central, albeit local, pellet facility where a consistent standard of feed pellet quality could be controlled. From there, a more locally-produced sustainable aquaculture feed supply could be distributed to fish farmers or through animal feed specialists. Such a venture is likely to succeed in New Zealand where increasing importance is placed on sustainably-produced food supplies from local providers.

\subsubsection{Plastics}

\section{$\underline{\text { 3.1.5.1 Fertiliser from biodegradable plastics }}$}

Although plastic production from renewable resources such as agricultural wastes can be dated to Henry Ford in 1910, their production did not gain momentum until two decades ago (Stevens, 2002). In light of escalating global petroleum prices, plastics derived from biological resources are now gaining independence and increased interest. Biodegradable plastics (bioplastics) are based on lactic acid sources in cellulose, lignin and starch polymers within crops, principally corn or organic wastes. Their end products are carbon dioxide and water, which can be assimilated into ecological systems through photosynthesis and typically decompose in approximately six weeks, after which they can be applied as fertiliser. By contrast, conventional plastics take more than 100 years to degrade (Stevens, 2002). Overseas research demonstrates that mechanical properties of bioplastics equals and/or exceeds conventional (ie. PET) plastics (sometimes with polymer enhancements) in terms of elasticity, tensile strength and elongation at breaking point (Siracusa et al, 2008). Additionally, the bioplastics industry is growing substantially in Europe with a $20-30 \%$ growth per annum in line with its plan to mitigate $\mathrm{CO}_{2}$ emissions (Kaeb, 2007). In New Zealand, the bioplastics industry has not yet materialised but has started to identify local agricultural wastes, including cow urea as sources of bioplastics, which could promote rural economic development (Farrin, 2007). Bioplastics seem appropriate in New Zealand for managing increased demand for plastics while helping to maintain material loop closure in harmony with natural biosystems as outlined in figure 2 .

\subsubsection{Plastic bottle tops as biofilm media for domestic wastewater treatment}

New Zealanders contribute 265-568 L of wastewater per person daily (Gunn, 1976). Simultaneously, 


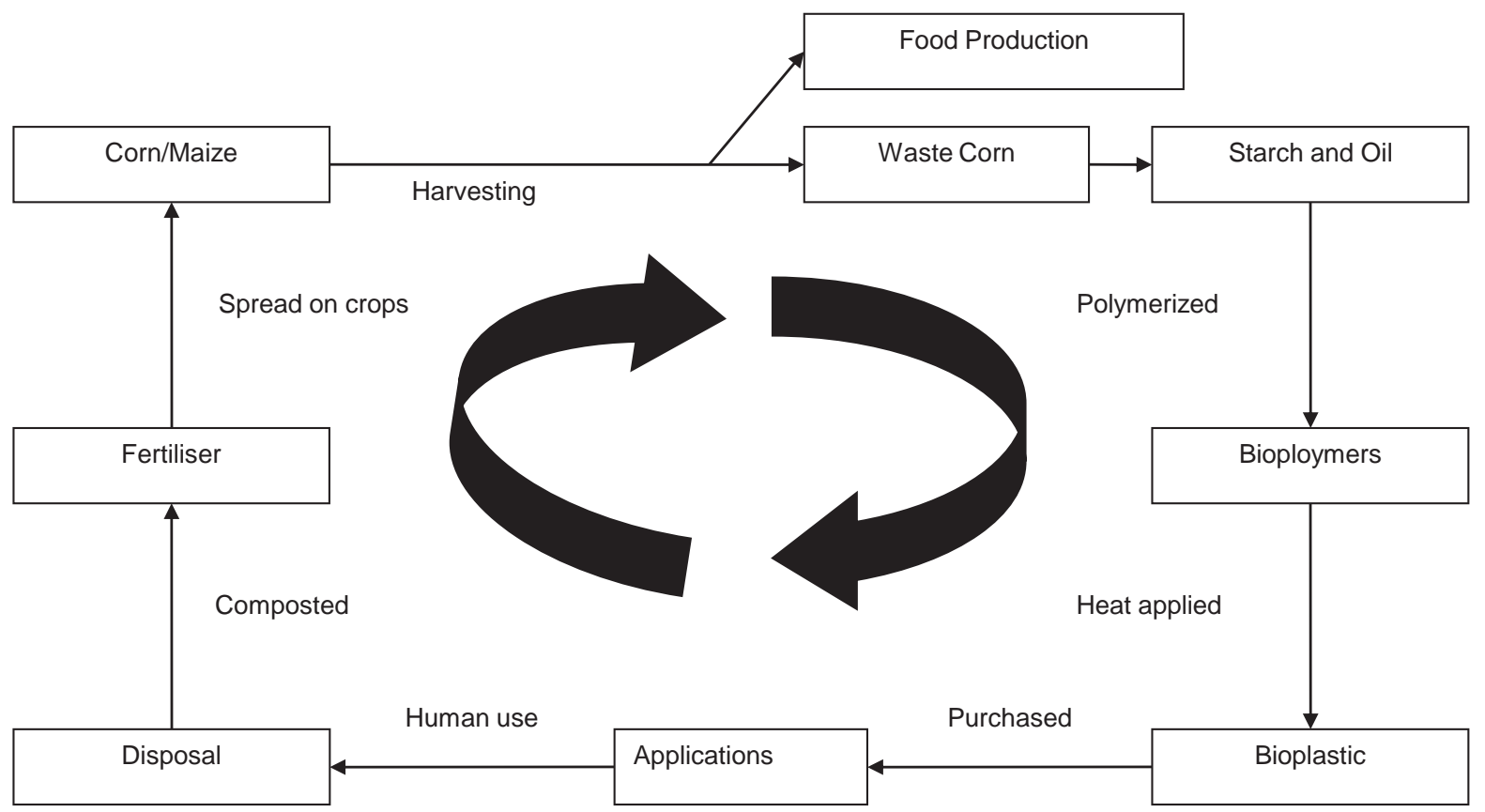

Figure 2: Intended life cycle of a biodegradable plastic.

$38,000 \mathrm{t} / \mathrm{a}$ of reusable plastic are collected, which constitutes approximately $18 \%$ of plastic consumed nationally. Only $9 \%$ of collected reusable plastic is managed in New Zealand, while the rest is exported to Asia (Boyle, 1999). Plastic bottle caps are not currently recycled and therefore are disposed to landfill in an unsustainable practice. A graduate of the Natural Resources Engineering program has established pilot-scale $\left(<2 \mathrm{~m}^{3}\right)$ on-site wastewater treatment systems around New Zealand, employing plastic bottle tops as the trickling filter media. This innovative biosystem comprised of reused plastic bottle tops is treating domestic grey water to a tertiary level of treatment within a few months when used in conjunction with a preceding vermiculture filter. Pathogens and petroleum oils are removed, and the bottle tops facilitate a large surface area and rough adhesive material for biofilm attachment within a small footprint. Although bottle tops are currently collected by colleagues (such as our research group) and friends of the system designer, larger-scale collection would need to be facilitated in order to implement more of these designs nationally. There is also scope to manufacture ready-made kits, which could be purchased and relatively easily assembled by registered plumbers. The estimated materials, assembly and installation cost is estimated at more than NZ\$300, but no sophisticated pumping apparatus or energy is required. By comparison, alternative grey water systems are estimated at NZ\$2000. Cost savings afforded from this design include reusing waste materials otherwise sent to landfill, a reduction in sewer waste loadings and saving on irrigation water. This project especially exemplified to current Natural Resources Engineering students how they can capitalise on waste resources through ecological engineering practice upon graduating since it was specifically developed by a predecessor of their engineering degree. Heightened interested occurred in this project as students appreciated the contextual application of their degree to practising engineering and enquired about job opportunities with the inventor of this system. It also served as a valuable case study to integrate triple-bottom-line principles for bettering New Zealand.

\subsection{Assignment marks}

Marks awarded for the assessed technical report, peer review, exam component and course overall, are shown in figure 3. Data are presented in a box plot and normalised so that student performance is compared to attainable marks for each assessment. Generally, students achieved good marks for their continuous assessment technical report $(77.5 \%$ median mark, compared to overall course of $68.3 \%$ ), which may be reflected by their interest and motivation in the assessment since it provided some choice of a specific waste topic. This result may also reflect enhanced learning afforded to students through iterative and constructive feedback. The course attained a higher rating compared to its college equivalents ( $\mathrm{O}^{\prime}$ Sullivan \& O'Donoghue, 2007), which was attributed to its program relevance and active learning model that lends itself to diverse learning styles. By comparison, students scored worse (median of $66.9 \%$ ) in the exam component, which accounted for $55 \%$ of the overall course mark. Tsai (2004) found that reproductive learning strategies such as exams and memorising reflect a lower level view of learning compared with constructive learning approaches afforded through applying contextual knowledge. A 3-hour exam setting is not conducive to deep learning where a 


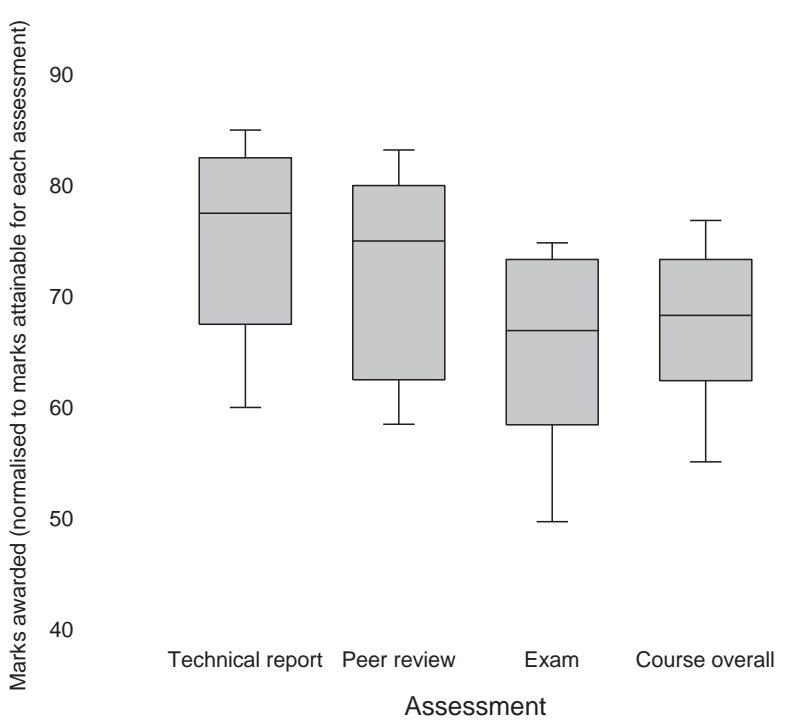

Figure 3: Marks awarded (normalised to marks attainable for each assessment) in the Ecological Engineering 2 course that recognised value from wastes. Horizontal lines in each statistical box represent median values, while upper $(90 \%)$ and lower $(10 \%)$ percentiles are given by the error bars, and upper $(75 \%)$ and lower ( $25 \%$ ) boundaries of each box defines these percentiles, $n=23$.

subject domain should be clearly understood and articulated, nor does it facilitate peer-learning. Lin \& Tsai (2009) reported that learning environments that are student-centred, instructor-facilitated and peer-interactive are more beneficial for engineering students, which was the approach facilitated in the study reported here. It is interesting to note that students typically rated each other's work to be good (75\% median and were slightly above marks awarded by the instructor(s)), but that substantial deviation in the marking existed. The opportunity to review peer reports equips students with the critiquing skills and appreciation for clarity required in competent engineering. Related research reports that although students find the task of peer-reviewing a challenging one; they benefit from the learning process (Hesterman, 2008).

\section{4}

\section{CONCLUSIONS}

Since engineers are inherently responsible for environmental modification through their professional activities, it is essential for engineering students to appreciate that sustainable development through engineering activities results from using natural resources wisely. Our final-year engineering students engaged in a prescribed desktop research project to realise capital in New Zealand waste streams. Triple-bottom-line principles were addressed in the research projects, all in a New Zealand context, while rudimentary cost-benefit analysis was conducted for the proposed solutions. Decentralised solutions were recognised, which offered numerous benefits over the status quo of disposing waste resources to landfill. These included: (i) reduced dependence on imported products; (ii) reduced freight costs; (iii) ecological, economic and social enhancement from coupling industrial processes; and (iv) reduced ecological footprints.

It is reported that real-world projects serve as a nexus between engineering theory and practice (Lamancusa et al, 2008), effective at providing students the chance to synthesise skills learnt in their courses into a cohesive problem-solving task in relevant contexts. The "waste to commodities" assignment detailed here aimed to achieve this integration while enhancing student's appreciation for the interdependence of our biotic and fiscal economies. While these undergraduate students subsequently engage in year-long research projects through another course (O'Sullivan \& Cochrane, 2009), they rarely focus on waste reuse. The main goal of these projects was to empower students to think creatively in pursuing alternative, yet realistic and cost-effective, methods for waste reuse and so aligned well with the principles of using ecology to steer technology for sustainable development (Boyle, 1999; Mitchell, 2000). It also aimed to facilitate creative entrepreneurship in an educational learning environment, which is recognised as an essential platform for technological intrapreneurship in the profession (Menzel, 2007). An engineering student should graduate with the knowledge and appreciation of how sustaining natural capital through professional practice is crucial for maintaining our integrated biotic and fiscal economies (Hawken et al, 1999; Painter, 2003). Ecological engineering education provides a platform for attaining these attributes, and its application through real-world research.

Successful outcomes of this model include motivating engineering students to consider creative yet pragmatic solutions for reusing wastes aligned with the New Zealand policy on waste minimisation and sustainable development. It also included engagement with end users and policy makers, as well as an introduction to the research domain providing a cohort of research-aware and experienced undergraduates for the graduate market.

\section{ACKNOWLEDGEMENTS}

The students of Ecological Engineering 2 (ENNR 405) from 2006 and 2008 are thanked for their cooperation in trailing the "waste to commodities" prescribed desktop research model. The University Centre for Teaching and Learning at the University of Canterbury is thanked for its encouragement in pursuing engineering education research. 


\section{REFERENCES}

Amari, A., Themelis, N. \& Wernick, I. 1999, “Resource recovery from used rubber tires", Resources Policy, Vol. 25, No. 3, pp. 179-188.

Baumann, H., Boons, F. \& Bragd, A. 2002, “Mapping the green product development field: engineering, policy, and business perspectives", Journal of Cleaner Production, Vol. 10, No. 5, pp. 409-425.

Bergen, S., Bolton, S. \& Fridley, J. 2001, “Design principles for ecological engineering", Ecological Engineering, Vol. 18, pp. 201-120.

Boyle, C. 1999, “Education, sustainability and cleaner production", Journal of Cleaner Production, Vol. 7, pp. 83-87.

Celik, O., Elbeyli, I. \& Piskin, S. 2006, “Utilization of gold tailings as an additive in Portland cement", Waste Management and Research, Vol. 24, No. 3, pp. $215-224$

Charmley, E., Nelson, D. \& Zvomuya, F. 2006, "Nutrient cycling in the vegetable processing industry: Utilization of potato by-products", Canadian Journal of Soil Science, Vol. 86, No. 4, pp. 621-629.

Clift, R. 1998, "Engineering for the Environment: the new model engineer and her role", Trans IChemE, Vol. 76, No. B, pp. 151-160.

Dickie, B. 2005, "Sustainable Management of Geothermal Resources in the Waikato Region, New Zealand", Waikato Regional Council Internal Report.

East Harbour Management Services, 2007, “Assessment of Possible Renewable Energy Targets - Direct Use: Geothermal".

Environment New Zealand, 2007, Environment New Zealand Project Team, Ministry for the Environment, Wellington, New Zealand, 456 pp

Hamilton, S., Gue, J. \& Socotch, C. 2007, “The use of Steel Slag in Passive Treatment Design for AMD Discharge in the Huff Run Watershed Restoration", Technical Report of the Ohio Department of Natural Resources, OH, USA.

Hawken, P., Lovins, A. \& Lovins, L. 1999, Natural Capitalism, Rocky Mountain Institute, Snowmass.

Head, P. 2009, "Entering the ecological age: the engineer's role", Civil Engineering, Vol. 162, No. 2, pp. 70-75.

Hesterman, D. 2008, “Peer assessment of past exam scripts", Australasian Journal of Engineering Education, Vol. 14, No. 2, pp. 57-76.
Jeuffroy, G. \& Sauterey, R. 1996, Cement Concrete Pavements, A.A. Balkema Publishers, Old Post Road, Brookfield, VT 05036, USA.

Johnson, A. 2006, "The Making of a New Discipline", International Journal of Engineering Education, Vol. 22, No. 1, pp. 3-8.

Kaeb, D. 2007, "Bioplastics: Time to Act", Packaging and Converting Intelligence, Vol. 2008, 21 September.

Karlik-Neale, M. 2006, "Product Stewardship Case Study for End-of-life Tyres", URS Consulting Engineers New Zealand Technical report.

Knuckley, I. 2004, “Utilisation of Seafood Processing Waste-Challenges and Opportunities", $3^{\text {rd }}$ Australian and New Zealand Soils Conference.

Krutz, G. \& Schueller, J. 2000, “Advanced Engineering: Future Directions for the Agricultural and Biological Engineering Profession", Journal of Agricultural Engineering Research, Vol. 76, No. 3, pp. 251-265.

Lamancusa, J., Zayas, J., Soyster, A., Morell, L. \& Jorgensen, J. 2008, “The Learning Factor: IndustryPartnered Active Learning", Journal of Engineering Education, Vol. 97, No. 1, pp. 5-12.

Larsen, T., Alder, A., Eggen, R., Maurer, M. \& Lienert, J. 2009, "Source Separation: will we see a paradigm shift in wastewater handling?", Environmental Science and Technology, Vol. 43, pp. 6121-6125.

Lawton, G. 2006, “Pee-cycling - Don't flush away that golden liquid. It's more valuable than what you think", New Scientist, Vol. 30, No. 23, pp. 45-47.

Lin, C.-C. \& Tsai, C.-C. 2009, "The Relationships Between Students' conceptions of Learning Engineering and Their Preference for Classroom and Laboratory Learning. Learning Environments", Journal of Engineering Education, Vol. 98, No. 2, pp. 194-204.

McCauley, C., O'Sullivan, A. Weber, P., Milke, M. \& Trumm, D. 2009, "Sulfate reduction and implications for metal removal in bioreactors from iron and aluminum dominated acid mine drainage", Water Research, Vol. 43, No. 4, pp. 961-970.

Meadows, D. H., Meadows, D. L., Randers, J. \& Behrens, W. W. 1972, The Limits of Growth: a report for the Club of Rome's project on the predicament of mankind, 205 pp.

Menzel, L. 2007, “On the way to creativity: engineers as intrapreneurs in organisations", Technovation, Vol. 27, No. 12 , pp. 732-743. 
Ministry of Economic Development, 2007, New Zealand Energy Strategy to 2050 - Powering Our Future, $107 \mathrm{pp}$.

Mitchell, C. 2000, “Integrating sustainability in chemical engineering practice and education: concentricity and its consequences", Trans IChemE, Vol. 78, No. B, pp. 237-242.

OceanaGold Corporation, 2008, www.oceanagold. com, accessed 13 April 2008.

Odum, H. \& Odum, B. 2003, “Concepts and methods of ecological engineering", Ecological Engineering, Vol. 20, pp. 339-361.

O'Sullivan, A. D. \& Cochrane, T. A. 2009, “Preparing Better Engineers: Compulsory Undergraduate Research Projects that Benefit Universities and the Profession", Proceedings of the 2009 Annual Conference on Engineering Education, American Society for Engineering Education, Austin, TX, USA, 14-17 June, $12 \mathrm{pp}$.

O'Sullivan, A. D. \& O’Donoghue, M. 2007, “Balancing Middle Earth through Interdisciplinary Engineering Education: Integrating Ecological Sustainability and Effective Research into a Professional Engineering Degree in New Zealand", Proceedings of the 2007 Conference on Engineering Education, International Network for Engineering Education and Research, Coimbra, Portugal, 2-7 September, pp. 1-6.

Painter, D. 2003, “Forty-nine shades of green: ecology and sustainability in the academic formation of engineers", Ecological Engineering, Vol. 20, No. 4, 267-273.
Pelletier, N. \& Tyedmers, P. 2007, “Feeding farmed salmon: Is organic better?", Aquaculture, Vol. 272, No. 1-4, pp. 399-416.

Shayan, A. \& Xu, A. 2004, "Value-added utilisation of waste glass in concrete", Cement and Concrete Research, Vol. 34, No. 1, pp. 81-89.

Siracusa, V., Rocculi, P., Romani, S. \& Dalla Rosa, M. 2008, "Biodegradable polymers for food packaging: a review", Trends in Food Science \& Technology, Vol. 19, No. 12, pp. 634-643.

Stevens, E. 2002, Green plastic: an introduction to the new science of biodegradable plastics, Princeton University Press.

Transit New Zealand, 2006, “Notes to the Specification for Base course Aggregate", TNZ M4, Technical specification \#24 (060418).

Truter, W. 2007, "Sustainable plant production on degraded soil/substrates amended with South African class F fly ash and organic materials", Doctoral Thesis, University of Pretoria.

Tsai, C.-C. 2004, "Conceptions of learning science amongst high-school students in Taiwan: a Phenomenographic analysis", International Journal of Science Education, Vol. 26, No. 14, 1733-1750.

TyreTrack, 2008, www.tyretrack.co.nz, accessed 5 May 2008.

Watzlaf, G. \& Ackman, T. 2006, “Underground Mine Water for Heating and Cooling using Geo-thermal Heat Pump Systems", Mine Water Environ, Vol. 25, No. 1, pp. 1-14. 


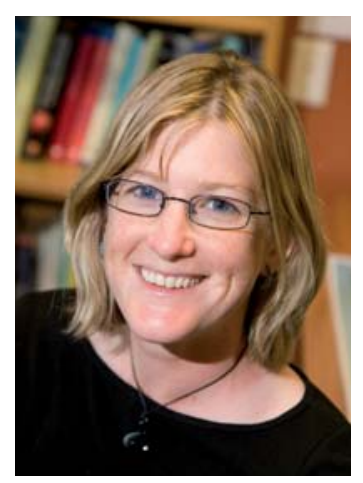

\section{AISLING O'SULLIVAN}

Dr Aisling O'Sullivan has been teaching and researching in the discipline of Ecological Engineering as a senior lecturer at the University of Canterbury since 2004. Prior to that, she was a visiting Post-Doctoral Teaching and Research Fellow at the University of Oklahoma in the USA and a Post-Doctoral Researcher at the National University of Ireland in Dublin. She teaches a wide range of environmental science principles and their engineering applications to large undergraduate classes $(n=200)$ through to smaller postgraduate classes $(n=$ 20) in engineering.

Aisling has co-led curricular developments, including undergraduate research projects, for the Natural Resources Engineering program. In 2007, she was recognised as one of the top 10 academics of excellent teaching practices at the University of Canterbury and in the same year was awarded a grant from the University Centre for Teaching and Learning for her paper titled "Balancing Middle Earth through Interdisciplinary Engineering Education". In 2008, she engaged in an Erskine Teaching Fellowship to advance her knowledge of environmental engineering curricula from some of the key Australian universities incorporating sustainability into their teaching.

Aisling has published in Engineering Education since 2006. Her other research interests focus on water quality monitoring and modelling, ecological treatment technologies, and waste reuse. She co-founded the Hydrological and Ecological Engineering research group at the University of Canterbury (www.hydroeco. info), which is a dynamic team of tenured academic staff, Post-Doctoral Fellows, $\mathrm{PhD}$, Masters and undergraduate honours research students in the Department of Civil and Natural Resources Engineering. 
